\title{
About Some New Methods of Analytical Philosophy. Formalization, De-formalization and Topological Hermeneutics
}

\author{
Janusz Kaczmarek \\ University of Łódź \\ Lindleya 3/5 Street \\ 90-131 Łódź, Poland \\ e-mail: janusz.kaczmarek@uni.lodz.pl
}

\begin{abstract}
:
In this article I want to continue the characteristics of philosophical methods specific to analytical philosophy, which were and are important for Professor Jan Woleński. So I refer to his work on the methods of analytical philosophy, but I also point out a few new methods that have grown up in the climate of studies of philosophers, especially analytical ontologists. I will therefore describe the following methods: generalization, specialization, formalization, de-formalization and topological hermeneutics. Instead of the term "method" I use interchangeably the terms "operation" or "procedure". I will show that each of these operations makes an important contribution to ontological investigations, and, in particular, to formal ontology.

Keywords: methods of philosophy, generalization, specialization, formalization, de-formalization, logical hermeneutics, topological hermeneutics, topological ontology, formal ontology, Jan Woleński.
\end{abstract}

\section{Methods, Procedures, Rules, Operations}

In this paper I refer to the work of Jan Woleński entitled "Kierunki i metody filozofii analitycznej" (Directions and methods of analytical philosophy) and in particular to its second part entitled "Methods of analytical philosophy". It discusses some methods characteristic for the analytical practice of philosophy, namely methods of: a) logical constructions (Russell, descriptive theory), b) explication (Carnap), c) paraphrases (Ajdukiewicz), d) presuposition (Strawson, Hart) and e) paradigm-case argument (Urmson, Hart) [25]. Of course, Professor Woleński has taken up the subject of methods in philosophy many times (comp [26] and [27]).

I will not discuss the methods indicated above, as such a description has been made many times [4], [7], [21], [25], [29]. On the other hand, I want to focus on newer methods or procedures of analytical philosophy, i.e. logical hermeneutics and topological hermeneutics, and I will try to show that some of the procedures considered within the phenomenological method are important for the analytical study of philosophical problems. Therefore I will present below:

(a) specialization and generalization operations,

(b) Husserl formalization and de-formalization operations, 
c) my own proposal, which I called topological hermeneutics and which I see as a complement to Wolniewicz's logical hermeneutics.

These methods will be partly confronted with the method of explication, paraphrases and logical constructions.

\subsection{Note on Method, Procedure and Operation - Ambiguity of these Terms and/or Concepts}

In many works we find descriptions of particular philosophical methods. Let us ask ourselves: what is a philosophical method? The answer is not easy, because when we look, for example, at the proposals of phenomenologists, one talks about the phenomenological method or methods, but also points to some special techniques (procedures, operations) such as eidetic reduction, epoche, variation or formalisation. It is similar in the framework of analytical philosophy, where the analytical method is talked about (aimed - following Bocheński - at language, analysis and logic), but also indicates some specific procedures such as Carnap's explication or Russell's descriptions.

Therefore, I propose that the method should be understood, in a working way, as a set of procedures characteristic of a given philosophical direction. A method understood in this way is then a set of detailed procedures, which I propose to call also tools or operations. Thus, for example, a phenomenological method is a specific way of reasoning and conducting research, in which we use (tools, operations) eidetic reduction, parenthesizing, variation, formalization, deformalization, specialization and generalization (perhaps not everything yet). In turn, in the analytical method, i.e. the one characteristic of the analytical philosophy of the 20th century, we will encounter such tools and operations as: application of some logic (e.g. classic, temporal Scott's logic, modal S5, etc.), axiomatization (cf. Wolniewicz's axioms for the lattice of the situations), development or use of the logical square, formal approach to definite descriptions and many others. Interestingly, both the phenomenological method and the analytical one can be characterized in a general way emphasizing their main "attitude". For example, Bocheński characterizes the analytical philosophy itself through keywords: language, analysis, logic and objectivity. From this we can conclude that the analytical method is characterized by: a) a turn to language and analysis of language, b) analysis of language using methods of logic, c) an attempt at objective analysis of what is on the side of reality and what can be expressed linguistically. Similarly, we can formulate basic axioms (or keywords) of phenomenology. Let us propose, therefore, at least the following postulates: a) turning towards the investigation of things, b) extracting what is essential (i.e., connected with the essence of the investigated thing), c) capturing what appears to our "self" as unreduced and free from any theoretical assumptions.

The brief proposal presented here may seem unjustified, but let us note that we find a similar approach in the book Bocheński [4]. Bocheński justifies that in contemporary philosophy we meet four basic methods [4, p. 14]:

1. the phenomenological method,

2. the language analysis,

3. the deductive method,

4. the reductive method.

In turn, in the book itself, Bocheński discusses in the following chapters the methods that correspond to the above, but are called respectively: the phenomenological method, semiotic methods, the axiomatic method and reductive methods. We have here some minor inaccuracies, because in the end we can ask: do we have a reductive method or rather (different) reductive methods; is language analysis the same as semiotic methods, etc.? From the text we learn, however, that Bocheński leans towards talking about the method as a specific style of conducting research that is most often appropriate for a given philosophical trend, while the terms procedure or operation should be used for more detailed tools. For example, eidetic reduction or epoche are called by Bocheński procedures, although he also uses the name "rule" [4, pp. 18-19].

The above mentioned demands do not aspire to a final solution. I just want to point out that the above problems call for a reliable and methodological reflection on philosophical methods and 
their detailed procedures (which I allowed myself to call also tools or operations). Therefore, in Part II we will give relevant examples of both analytical and phenomenological work.

\subsection{Validation/Justification of Philosophical Methods}

When Ajdukiewicz was proposing his method of paraphrases, he noticed that it should be justified, validated. I think that the problem of justification concerns every method, including any other presented in this work or discussed by Woleński, Bocheński, Stegmueller. Let us therefore look at the problem of validation in Ajdukiewicz's view. In the article On the Applicability of Pure Logic to Philosophical Problems from 1934 he writes:

The apparent use of logic in solving philosophical problems formulated in natural language does not consist, therefore, in the deduction from logical theorems by legitimate substitution of conclusions which contribute to the solution of those problems. The procedure which has all the appearances of such application in fact consists in the construction in a natural language of sentences whose structure is isomorphic with the structure of logical theorems, i.e. in paraphrasing logical sentences into sentences with variables ranging over different domains of substitution than logical variables. It is only from such paraphrases that one may derive by substitution consequences relevant to philosphical problems formulated in a natural language. There is no doubt that the construction of such a system of sentences is desirable, for it would constitute the logic of ordinary language. However, those sentences, as paraphrases of universal logical sentences, require a validation which the existing contemporary logic is unable to supply.

They could be validated as analytic sentences through a meaning analysis of the expressions of ordinary language. In the search for this validation one might use the phenomenological method. Alternatively, they could be justified by elevating them to the rank of postulates which - disregarding the meanings expressions have in ordinary language - would fix those meanings arbitrarily. This second method is more promising, it seems, than the phenomenological one which should be tried nevertheless. One must not forget, however, that if the second of the two methods is used the expressions of the language may acquire meanings different from those they had previously. Hence the same verbal formulations might not express the same problems. However, this need not necessarily be regrettable (p. 93, The Scientific World Perspective).

Ajdukiewicz, as we can see, points to two paths leading to the validity of sentences being paraphrases of generalised logical sentences. The first one is to consist in the meaning analysis of sentences-paraphrases and treating them as analytical sentences. Then - in his opinion - the phenomenological method could be helpful. The second would consist in treating these sentences as postulates. Ajdukiewicz does not explain in detail what the application of the phenomenological method is to consist in. We can only guess that Husserl's analyses of expressions, meanings, senses, sentences, judgments proposed in Logical Investigations should be used. On the other hand, treating sentences (paraphrases) as postulates results in the unambiguity of terms but at the same time introduces arbitrary meanings that do not have to coincide with the meanings of expressions occurring in philosophical problems.

It is interesting that Bocheński also mentions the need to authorise (validate) the method. Bocheński directly writes about the justification of the phenomenological method, the justification of language analysis and the justification of formalism. I conclude from this that each method, and perhaps also the individual procedures of a given method, must make sure to reflect on their justification. For example, according to Bocheński, justification for formalism can be found in a) possibilities (thanks to formalism) of going beyond what is intuitively obvious, b) clear separation 
and explanation of concepts, c) elimination of hidden assumptions, and finally d) possibilities of different interpretation of what is formal and universal [4, pp. 40-41].

\section{Husserl and Analytical Tools}

Husserl, the founder of phenomenology, develops and uses the phenomenological method in his studies. In the initial pages of his Ideas I, however, he draws attention to some detailed tools (operations, procedures, rules), which are used or should be used by an ontologist (because here, in paragraphs $7-17$, it is not so much about phenomenology as it is, above all, about formal ontology and regional ontologies). These tools are: specialisation, generalisation, formalisation and deformalisation. Let us look at them and show that they are also tools used by analytical philosophers. I personally use them when I conduct ontological research.

Phenomenology is for Husserl a field of analysis through which one prepares the ground for particular sciences and philosophical problems. These analyses are aimed at examining the essence of various objects and the pure form of the object in general. The ontologist does the same - let us underline this - as well. Husserl writes about this subject in this way [8, p. 19] of the original edition:

Any concrete empirical objectivity finds its place within a highest material genus, a "region," of empirical objects. To the pure regional essence, then, there corresponds a regional eidetic science or, as we can also say, , a regional ontology. In this connection we assume that the regional essence, or the different genera composing it, are the basis for such abundant and highly ramified cognitions that, with respect to their systematic explication, it is indeed worth speaking of a science or of a whole complex of ontological disciplines corresponding to the single generic components of the region.

And then on [8, p. 19]:

Any science of matters of fact (any experiential science) has essential theoretical foundations in eidetic ontologies. For (in case the assumption made is correct) it is quite obvious that the abundant stock of cognitions relating in a pure, an unconditionally valid manner to all possible objects of the region - in so far as these cognitions belong partly to the empty form of any objectivity whatever and partly to the regional Eidos which, as it where, exhibits a necessary material form of all the objects in the region cannot lack significance for the exploration of empirical facts.

Therefore, when we consider the operations of transition to species or genera (specialisation and generalisation), we are in the field of properly ordered essences - from the highest to the lowest genus. Again, let us give the floor to Husserl himself [8, p. 25].

We now need a new group of categorial distinctions pertaining to the whole sphere of essences. Each essence, whether materially filled or empty (thus, purely logical), has its place in a hierarchy of essences, in a hierarchy of generality and specificity. This series necessarily has two limits which never coincide. Descending, we arrive at the infimae species or, as we also say, the eidetic singularities; ascending through the specific and generic essences, we arrive at a highest genus. Eidetic singularities are essences which necessarily have over them "more universal" essences as their genera, but do not have under them any particularizations in relation to which they would themselves be species (either proximate species or mediate, higher, genera). In like fashion, that genus is the highest which has no genus over it. 
Let us now present a concrete example of hierarchically ordered essences. Referring to the studies of philosophers, we can indicate the well-known Porphyry tree (arbor porphyriana) [10, 23].

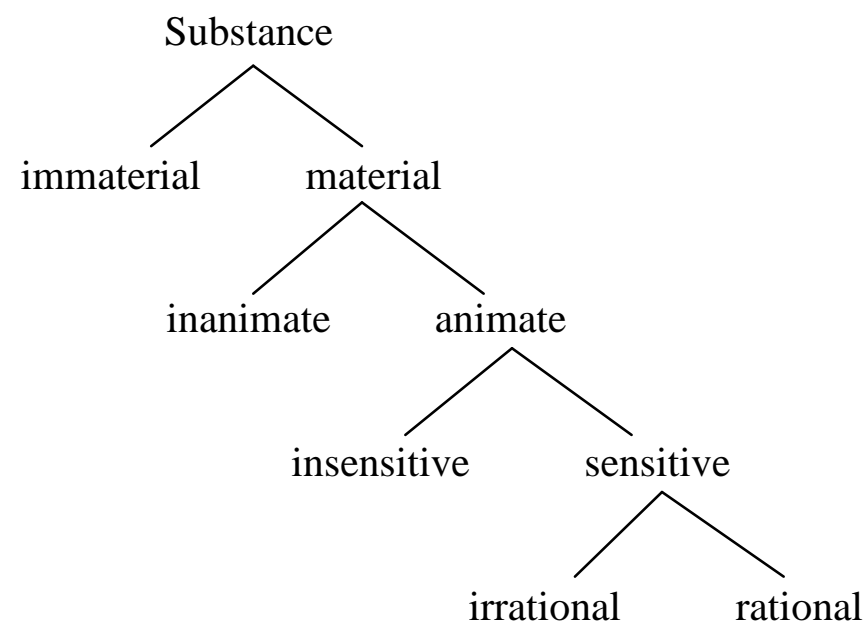

Let's also establish that:

(a) the substance (as a universal) is characterised by its content (ideal quality, in Ingarden terminology): "being a substance",

(b) material substance by: being a substance and being material (I omit quotation marks),

(c) immaterial substance by: being a substance, being immaterial; example: angel,

(d) sensitive substance by: being a substance, being material, being sensual,

(e) rational substance by: being a substance, being material, being sensual and being rational.

I skip the description of the other objects, because it is easy to guess. Furthermore, let us notice that an irrational substance could be replaced by many other "objects" such as "equines", "elephants", etc. For example, in zoology, a horse is characterized as: multicellular, vertebrate, mammal, and odd-toed (in short); let us treat it as having the following content: being a substance, being material, being sensual, being odd-toed.

Next, the particular names in the Porphyry tree should be treated as names for so-called universal objects. If there are some dashes down from a certain inscription, this inscription is the name of the genus, and if there is nothing underneath, this is the name for the species. Thus, when Husserl speaks of the lowest varieties of universal objects, he indicates the species (not the genera). So if a human being (a rational substance) is a species, or the lowest kind, then there is no such thing as a species or essence: male, female, hairdresser or philosopher. Species (but also genera) are sometimes called essences by Husserl (the Greek term eidos is sometimes translated as idea, sometimes as essence). Specialisation is the transition from a genus (e.g. animate substance) to a lower genus or species (e.g. to a sensitive substance or immediately to a rational substance). Generalisation goes in the opposite direction (e.g. from a human being to an animate or material substance).

Things are obvious when we have a tree. But how do we get it? Let us notice that also the above tree can "miss" essences, although the philosophical tradition convinces us that e.g. "animality and rationality" is the essence of man. Zoologists and philosophers build different "systematics" of animals, plants and man (one of the animals). The aim of Husserl is therefore to bring out what is the essence of what is alive, what is the essence of man, and so on. In his Ideas (that is, in Volume II) he gives, among other things, an answer that can be given briefly as follows: the essence of an organic substance is: being a substance and being alive (of course, we could discuss both at length). What is more, I would also like to stress that the transition from a certain kind, to a kind that is directly inferior (e.g. from what is animate to what is sensitive) does not have to be made by indicating a single content. Content: "being sensitive" or "being reasonable" are usually very complex contents. 
Ingarden understood these species and genera (he called them, in general, ideas) as follows (I will give it by example and in a formalized way). ${ }^{1}$ In the material substance as such we have certain contents, let there be five of them, from $u_{1}$ to $u_{5}$, which together define what is substantiality (being a substance). Furthermore, we have, let us say, four contents, let us mark them with the letter $w$ in the appropriate indexes, which characterize what we briefly express as "materiality". This is not all, because in such an idea there are still - according to Ingarden - some variables, i.e. other contents, but not yet defined, and which concern organicity (the letters $x$ ), sensuality $(y)$ or rationality $(z)$. If we define the letters $x$ in the appropriate indexes negatively, we obtain an inorganic material substance, an example of which is stone, while if we define the letters $x$ and $y$ positively, we obtain the idea of material substance, organic and sensual. However, a problem arises: can we talk about a material, inorganic and sensitive substance? Is there such an idea, such an essence? Well, here is the biggest problem that the philosopher is trying to solve. Husserl's answer, and Hartmann in particular later, goes in this direction to discover that "there is no sensuality without organicity". It is true that Thomas Aquinas taught about angels, which were immaterial and rational substances, but in our real world, rational beings (man) are only those which by necessity must also be: material, organic and sensitive (let us note that Kant has already taught that all cognition begins with intuition, with sensuality), so without senses there would be no reason, and without organic there would be no senses.

After these explanations, it is clear that specialization is the transition from a higher order essence to a lower order essence. But: not blindly! Not everything is an essence, not every filling with the contents of a higher essence hits a lower kind of essence. For example, there is no such thing as a material, inanimate, insensitive and rational substance ${ }^{2}$. Generalization in turn is the reverse process. But also here we can see that if we take the essence of the human being, we cannot make any content variable (inverse to filling it with content), e.g. (the answer is partly in the language of science) we cannot move from the idea of the human being to the idea of something that does not have a nervous system or is not a vertebrate, although it remains (sic!) reasonable.

Remark. The Porphyry tree is a good example of classification or so-called logical partition. The classification assures us that by distinguishing certain subgenera, we distinguish those subgenera whose subordinate individuals are all individuals of a given type, and those subgenera are such that the subordinate individuals do not simultaneously fall under other subgenera. However, the following problem arises: when we distinguish in a kind of polygon such as the regular and non regular polygon or the concave and convex polygon, which of these partitions is appropriate? Which of these partitions "hits" the essence? Of course, mathematicians are not interested in such problems today. It is a philosophical problem. A mathematician is interested in concepts (or mathematical structures and objects), a philosopher is interested in essences.

Let us now move on to the next pair of operations: formalization and de-formalization. These are operations different from the specialisation and generalisation operations just discussed. In the Paragraph 13 Generalization and Formalization Husserl explicitly states [8, p. 26]:

One must sharply distinguish the relationships belonging to generalization an specialization from the essentially heterogeneous relationships belonging, on one hand, to the universalization of something materially filled in the sense of pure logic and, on the other hand, to the converse: the materialization of something logically formal. In other words: generalization is something totally different from that formalization which plays such a large role in, e.g., mathematical analysis; and specialization is something totally different from de-formalization, from "filling out" an empty logico-mathematical form or a formal truth.

Husserl explains these difficult operations (formalization and de-formalization) by analysing examples from the field of mathematics (geometry) and the sphere of sensual quality [8, p. 26]. 
Accordingly, the subordinating of an essence to the formal universality of a pure-logical essence must not be mistaken for the subordinating of an essence to its higher essential genera. Thus, e.g., the essence, triangle, is subordinate to the summum genus, Spatial Shape; and the essence, red, to the summum genus, Sensuous Quality. On the other hand, red, triangle, and similarly all other essences, whether homogeneous or heterogeneous, are subordinate to the categorical heading "essence" which, with respect to all of them, by no means has the characteristic of an essential genus; it rather does not have that characteristic relative to any of them. To regard "essence" as the genus of materially filled essences would be just as wrong as to misinterpret any object whatever (the empty Something) as the genus with respect to objects of all sorts and, therefore, naturally as simply the one and only summum genus, the genus of all genera. On the contrary, all the categories of formal ontology must be designated as eidetic singularities that have their summum genus in the essence, "any category whatever of formal ontology."

Apart from explaining what formalizing and de-formalizing is, Husserl points out the differences of the above operations in relation to the operations of generalization and specialization. Nevertheless, let us give some more examples from philosophical fields.

1) In the Porphyry tree, we have indicated specific materially defined essences. Ingarden, as I wrote above, understands them properly. Note that each essence has a certain amount of content that has appeared at a higher level and a new set of content that appears as a filling of the higher level. The latter set is that which in scholastics corresponds to the species difference, the former to the directly superior genus. Well, we can say that when we consider an essence (universal object) as an empty thing, we are not interested in material terms, but only in the pure form of the essence, in which we discover the "generic part" and the "species difference part". This is formalization!

2) Let us consider the following reasoning (argumentation):

(A) If the cube of sugar is placed in boiling water, then the cube will dissolve

And

The cube was placed in boiling water,

Thus

The cube will dissolve,

This is an example of some detailed (material) reasoning. But when the logician comes to the conclusion that the general scheme of this inference is a formula

$(*)((\alpha \rightarrow \beta) \wedge \alpha) \rightarrow \beta$,

we have an example of formalization. Of course, the formula $\left(^{*}\right)$ is not any genus (kind) in relation to reasoning (A). Husserl explains it as follows [8, pp. 26-27]:

It is clear, similarly, that Any determinate inference, e.g., one ancillary to physics, is a singularization of a determinate purely logical form of inference, that any determinate proposition in physics is a singularization of a propositional form, and the like. The pure forms, however, are not genera relatively to the materially filled propositions or inferences, but are themselves only infimae species, namely of the purely logical genera, proposition, inference, which, like all similar genera, have as their absolutely highest genus "any signification whatever". 
3) In the monograph [11] I recalled Wolff's views on being. For Wolff, being is what is noncontradictory, what is possible. Every being is determined by the essential, attributive and contingent features (properties). It is usually stated in the philosophical literature that organicity, animality or rationality are examples of essential qualities. Then the attributes will be the ability to use language or create knowledge, while the contingent features will include being a philosopher or having two children. However, when we point to such features of particular entities or classes of entities, then we are in the area of material, regional ontology. An important result of Wolff's ontology, however, is that he formalized the concept of being. How did he do this? He did it by indicating three classes of properties and establishing mutual relations between them. For example, essential properties are independent of each other, attributive properties are generated by essential properties, while contingent features are those that are inconsistent with essential properties. These relationships and their properties apply to each material domain and are independent of each domain. Therefore Wolff gave a formal approach to being, and the transition from these and these material domains (e.g., from animal existence) to the formal approach of being is a formalization (compare details of this analysis in [11, pp. 40-43] and [28]). In turn, the transition from a formal approach of being to an animal or human being, which is not easy and is done as a result of proper filling with content, is what Husserl calls a de-formalization operation.

\section{Topological Hermeneutics}

In this chapter I would like to draw attention to the topological ontology that has been developing in recent years and its method, which I call topological hermeneutics. Topological ontology (in short topoontology) as a fragment of topological philosophy is an analysis of ontological concepts, assumptions, theorems and problems using concepts, statements and tools of general topology. This kind of analysis has been undertaken in the works of Mormann [17], Schulte and Cory [19], Skowron [20], [22], and Kaczmarek [13], [14], [15]. What is topoontology and what is topological hermeneutics? I will explain this, I hope, more fully when I present particular ontological solutions using general topology tools.

I compare the study of ontology problems using topological tools with the studies of Wolniewicz, who presented a precise interpretation of Wittgenstein's ontology by applying the lattice theory (comp. Wolniewicz [30] and [31]). What is more, Wolniewicz proposed the so-called logical hermeneutics, which allows for the interpretation and comparison of certain theses of Wittgenstein's ontology and Hume's epistemology in the lattice theory ${ }^{3}$. My proposal is to use a general topology to interpret Wittgenstein's ontology, Hume's epistemology and Leibniz's ontology (monadology). It turns out that the Wolniewicz's lattices can be understood as lattices composed of certain topological spaces and thus we obtain a generalisation of Wolniewicz's theory. Topological hermeneutics therefore concentrates on the fact that it incorporates various notions and theorems of ontology in the language of general topology and not (only) in the language of the lattice theory or logic. In my opinion, as I will try to demonstrate, such an approach results in new and interesting formal theorems that have ontological significance. So let's move on to the concrete ones. I will focus mainly on the topological interpretation of small fragments of Wittgenstein's logical atomism ontology (and Russell's, because they worked on these issues together).

We will conduct our considerations on the example of two lattices examined by Wolniewicz in [30, p. 81]: the first lattice is an atomic lattice with $W$-independent elements, the second is a nonatomic lattice with $W$-independent elements. 


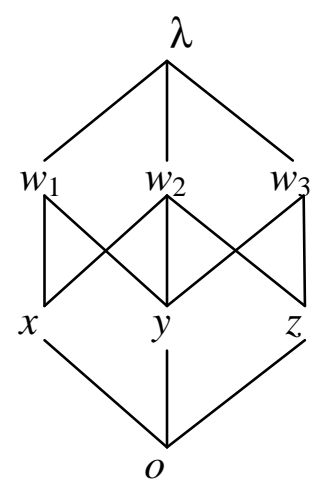

Figure 1. Atomistic lattice.

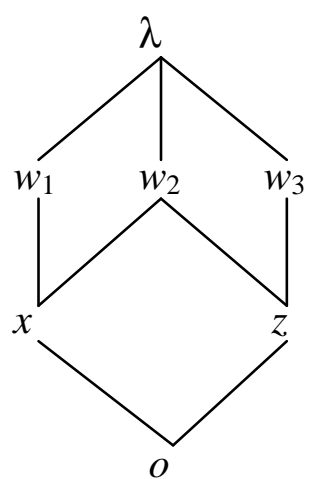

Figure 2. Non-atomistic lattice.

The elements of these lattices are interpreted as situations: $o$ is an empty situation, $\lambda$ is an impossible situation and the others are proper situations. Situations $x, y$ and $z$ are atomic and correspond to the Wittgenstein's states of affairs. In turn, $w_{1}, w_{2}$ and $w_{3}$ are called possible worlds, and we can interpret them as conjunction (splice, concatenation) of atomic situations.

Before we move on to further considerations, let us explain three concepts: atomistic lattice, non-atomistic lattice and $\mathrm{W}$-independence of situations. The concept of the atomic lattice - different from the concept of the atomistic lattice - and concept of topological space - will also help. Definitions of these concepts can be given in purely formal language (in the language of lattice theory). However, we will abandon this way of defining and present these definitions in natural language (using maximum precision).

There is a certain order < in each lattice $\boldsymbol{K}$. For example, in the Lattice from diagram 2: $x<$ $w_{1}$ and $x<w_{2}$. The smallest element $o$ is called a zero of the lattice, and the largest element $\lambda$ is called a unity of the lattice. For any $a \in \boldsymbol{K}$ and $a \neq o$, the set $[o, a]=\{x \in \boldsymbol{K}: o<x<a\}$ is called a segment. The element $a$ (different from zero) of the lattice is called an atom if the segment $[o, a]$ is two-element one.

1) a lattice $\boldsymbol{K}$ is atomic iff in any interval $[o, a]$ there is an atom; as you can see, both lattices above are atomic;

2) a lattice $\boldsymbol{K}$ is atomistic iff each element of the lattice is the supremum of some set of atoms; in the above examples, the first lattice is atomistic and the second is not; for example, in figure 2, element $w_{1}$ is not the supremum of any set of atoms;

3 ) two elements $x, y$ of the lattice $\boldsymbol{K}$ are called $W$-independent (Wittgenstein's concept of independency) iff infimum of $x$ and $y$ is $o$ whereas supremum $x$ and $y$ is different from $\lambda$; for example, element $x$ i $y$ of Figure 1 are independent, but $x$ and $w_{3}$ are dependent;

$4)$ if $X$ is Any set, then the pair $\left(X, \tau_{X}\right)$ will be called topological space, where $\tau_{X}$ is Any family of subset of $X$ iff the family fulfils the following conditions: a) the empty set $\varnothing$ and $X$ belong 
to $\left.\tau_{X}, b\right)$ any union of subsets of $X$ belongs to $\tau_{X}$ and c) intersection of finite number of subsets of $X$ belongs to $\tau_{X}$; an example of a topological space is a pair $\left(X, \tau_{X}\right)$, where $\tau_{X}$ is a family of all subsets of a set $X$; this space is called discrete space; another example is the so-called Euclidean space on a set of real numbers $\boldsymbol{R}$, where $\tau_{R}$ is composed of sets which are the union of any number of intervals $(a, b)$, for $a, b \in \boldsymbol{R}$.

It turns out that the above presented lattices can be transformed into lattices composed of topological spaces. I then propose the following procedures for conversion. In Figure 1, we convert:

$o$ into $\varnothing$,

$x, y$ and $z$ to (respectively) $\{x\},\{y\}$ and $\{z\}$,

$w_{1}, w_{2}, w_{3}$ we convert into $\{x, y\},\{x, z\}$ and $\{y, z\}$.

Then it is easy to see that e.g. the family of sets included in $w_{2}$ i.e. the family $\{\varnothing,\{x\},\{z\}$, $\{x, z\}\}$ together with the set $\{x, z\}$ is a topological (discrete) space, and the appropriate lattice can be visualized as follows:

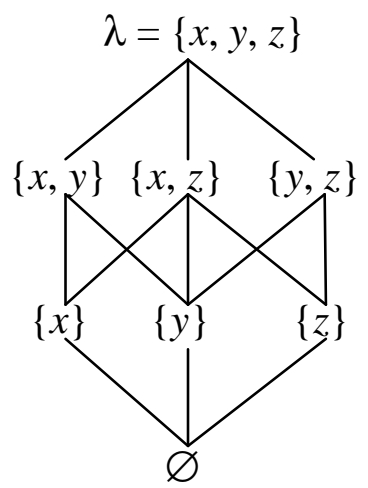

Figure 3. Atomistic lattice with three topological spaces.

We do the same with the lattice presented in Figure 2. Here, however, both $w_{1}$ and $w_{3}$ are not suprema of the selected group of atoms and therefore we have to propose that $w_{1}$ we convert to $\{x$, $\left.y_{1}\right\}$ and $w_{3}$ to $\left\{y_{2}, z\right\}$. Then we again see that e.g. the family of sets included in $w_{1}$ i.e. the family $\left\{\varnothing,\{x\},\left\{x, y_{1}\right\}\right\}$ together with the set $\left\{x, y_{1}\right\}$ constitutes a topological space. It is easy to see that this space is not discreet.

The above procedure allows us to obtain an interesting topoontological statement. Namely,

Fact. Any atomic lattice is atomistic when it is composed of discrete topologies.

In this way we received the necessary condition for each element in the atomic lattice to be the supremum of a certain set of atoms (in the language of general topology: that each set is the union of a certain set of singletons). Atomicity and atomisticity are, according to Wolniewicz, the key assumptions of Wittgenstein atomism. Following Wolniewicz, we can say that every possible world, including our real world, according to Tractatus, can be interpreted as a multiplicity or total of all atomic states of affairs that are $W$-dependent.

In the paper [14] I also considered non-atomic lattices, i.e. ones which do not meet the condition that in any segment an atom exists. Is it worth to consider such lattices? Well, Wittgenstein assumed that the analysis of a sentence cannot be carried out indefinitely, so there must be so-called elementary sentences and consequently their correlations on the side of reality, i.e. atomic states of affairs. However, when asked about an example of a simple sentence that refers to an atomic state of affairs, he replied that he did not know. Nota bene in Tractatus we will not find such an example either. The problem is that a simple sentence of the type

'The weather is nice' 
can be seen as a conjunction of sentences

'It's sunny and warm.'

But then a simple sentence

'It's warm'

we can interpret as a conjunction of sentences, say,

'It's such a such temperature and it doesn't blow'

and, theoretically, we can further analyze other simple sentences (e.g. 'It is sunny' we can describe by the state of cloudiness and type of clouds). This makes us think that it is worthwhile to study such lattices, in which a given situation (in topology a certain set) can be analyzed by smaller sets, e.g. $A=B \cup C$, next $C=D \cup E \cup F$, and thus $A=B \cup D \cup E \cup F$, and so on. The use of topological spaces allows for the interpretation (modelling) of both atomic and non-atomic theses.

In this paper I also took up another problem that was suggested by P. Weingartner: what is the negation of the atomic state of affairs and is it also an atomic state of affairs? It turns out that the answer is the following:

a) in Wolniewicz's lattices, the negation of an atomic state of affairs may be another atomic state of affairs or, also, a complex situation (consisting of several states of affairs); let us refer to Figure 1; elements $x$ and $z$ are atoms, $w_{3}$ is not an atom and is the supremum of $y$ and $z$; it turns out, however, that the infimum of $x$ and $z$ is the zero of the lattice, while the supremum of $x$ and $z$ is the unit of the lattice, which means that $z$ is the negation of the atom $x$; the same is true for the $x$ and $w_{3}$; their infimum is zero and the supremum is the unit of the lattice; conclusion: $w_{3}$ is also the negation of $x$; the negation of $x$ is therefore both the atomic and the complex element,

b) another result is obtained in the case of non-atomic lattices; in [14] I showed that there are lattices consisting of topological spaces, in which for any situation (a set) there is no negation of it (complement of such a set is not a part of the lattice $)^{4}$. Ontologically we can interpret this result as follows: when we consider possible worlds, including our real world, all situations or states of affairs are positive. No situation is a negation of any other. This answer is consistent with the theses of those ontologists who doubt the existence of negative states of affairs or negative situations.

\section{Summary and Final Remarks}

In this piece I tried to show that the methods of analytical philosophy indicated by Woleński can be supplemented. After all, a few decades have passed. So I added the methods or operations proposed by Husserl and presented briefly the method (or tool) called here topological hermeneutics. I hope that Professor Woleński will agree with this proposal.

Let us try to sum up: what is topological hermeneutics as a method or a certain tool within an analytical method? Ontological hermeneutics is doing so:

1) considers the problems of classical ontology (e.g. the main theorems of logical atomism (among others, atomicity), what is a monad (Leibniz's ontological atomism), what are perceptions and how they relate to the situation (Hume, Wolniewicz's logical hermeneutics)),

2) formalises the theses (but also concepts) studied in the language of general topology, because, in the case of the interpretation of logical atomism in Wolniewicz's view, it turns out that this interpretation can be generalized to study both the approach characteristic for Wittgenstein's and Russell's atomism and the approach opposite to atomism,

3) derives formal theses concerning atomism and non-atomism in the language of general topology, 
4) leads to new conclusions which cannot be proved on the basis of the theory of Wolniewicz's lattices (cf. Fact given above); these conclusions shed new light on the situation ontology and logical atomism,

5) derives formal theorems, which can be interpreted ontologically, but also, and we hope so, can influence the search for mathematicians themselves.

There is one more problem that I have set myself as a task for the future. It is about the validation (Ajdukiewicz's term) or justification (Bocheński's term) of the operations, tools, methods discussed. In the case of justification I think that points a) - d) indicated in the final part of Paragraph 1.2 of this paper can be accepted as justification for the topological hermeneutics method. Perhaps we should look for more justifications. However, in the case of Ajdukiewicz the matter is slightly different. Ajdukiewicz tries to find a certain logical theory (a certain set of logical sentences) that would be the basis for philosophical claims. This basis would guarantee the validation of philosophical theorems (which are usually given in natural language). Ajdukiewicz did not see a solution when he was writing about it, and I do not see a solution today either. This should be put as a problem. I think it is a key problem. We may ask: for which philosophical field is it a key problem? The short answer is: for everyone who considers the results of formal sciences (these, according to Aristotle, were a tool of philosophy). So let it be a problem which will be dealt with by ontologists and logicians.

\section{Acknowledgments}

This paper is supported by the National Science Centre, Poland, No 2017/27/B/HS1/02830.

\section{References}

1. Ajdukiewicz, K. On The Applicability of Pure Logic to Philosophical Problems, In K. Ajdukiewicz The scientific world-perspective and other essays, 1931-1963, Synthese Library, vol. 108, Dordrecht, Holland: D. Reidel Publishing Company, 1978 (1934), pp. 90-94.

2. Ajdukiewicz, K. A Semantical Version of the Problem of Transcendental Idealism, In K. Ajdukiewicz The scientific world-perspective and other essays, 1931-1963, Synthese Library, vol. 108, Dordrecht, Holland: D. Reidel Publishing Company, 1978 (1937), pp. 140-154.

3. Ajdukiewicz, K. The scientific world-perspective and other essays, 1931-1963, Synthese Library, vol. 108, Dordrecht, Holland: D. Reidel Publishing Company, 1978.

4. Bocheński, I. M. The Methods of Contemporary Thought, New York: Harper Torchbooks, 1968 (first ed. Die zeitgenössischen Denkmethoden, Dalp TB, Bd. 304, Bern: Francke, 1954).

5. Czeżowski, T. Logika. Podręcznik dla studiujacych nauki filozoficzne (Logic. Handbook for Students of Philosophy), Warszawa: Państwowe Zakłady Wydawnictw Szkolnych, 1949.

6. Glock, H-J. A Wittgenstein Dictionary, Oxford: Blackwell Publishers, 1996.

7. Hempel, C. G., H. Putnam, and W. K. Essler (eds.). Methodology, Epistemology, and Philosophy of Science: Essays in Honour of Wolfgang Stegmüller on the Occasion of his 60th Birth Day, June 3rd, 1983, Reprinted from the Journal Erkenntnis 19 (1, 2 and 3), Springer Verlag, 1983.

8. Husserl, E. Ideas Pertaining to a Pure Phenomenology and to a Phenomenological Philosophy, trans. by F. Kersten, The Hague/Boston/Lancaster: Martinius Nijhoff Publishers, Kluwer Academic Publishers Group (first edition: 1913), 1983.

9. Ingarden, R. Controversy over the Existence of the World, Vol. I, Translated and annotated by A. Szylewicz, Frankfurt am Main: Peter Lang GmbH, Internationaler Verlag der Wissenschaften, pp. 320 (first edition: Kraków: PAU, 1947/48), 2013.

10. Kaczmarek, J. On the Porphyrian Tree Structure and an Operation of Determination, Bulletin of the Section of Logic 31/1, 2002, pp. 37-46.

11. Kaczmarek, J. Indywidua. Idee. Pojęcia. Badania z zakresu ontologii sformalizowanej [Individuals. Ideas. Concepts. Investigating into Formalised Ontology], Łódź: Wyd. Uniwersytetu Łódzkiego, 2008. 
12. Kaczmarek, J. What is a Formalized Ontology Today? An Example of IIC, Bulletin of the Section of Logic 37 (3-4), 2008, pp. 233-244.

13. Kaczmarek, J. Atom ontologiczny: atom substancji [Ontological atom - atom of substance], Przeglad Filozoficzny. Nowa Seria R. 25, nr 4 (100), 2016, pp. 131-145.

14. Kaczmarek, J. Ontology in Tractatus Logico-Philosophicus: A Topological Approach, In G. Mras, P. Weigertner, and B. Ritter (eds.), Philosophy of Logic and Mathematics, Berlin/Boston: De Gruyter, pp. 245-262, 2019.

15. Kaczmarek, J. On the Topological Modelling of Ontological Objects: Substance in the Monadology, In B. Skowron (ed.), Polish Contemporary Ontology, Berlin/Boston: De Gruyter, pp. 149-159, 2019.

16. Kuratowski, K. Wstęp do teorii mnogości $i$ topologii, (wraz $z$ dodatkiem R.Engelkinga: Elementy topologii algebraicznej), [Introduction to Set Theory and Topology (with a supplement by R. Engelking: Elements of algebraic topology)], Warsaw: PWN, (see also: Kuratowski, Topology, vol. I, 1966, vol. II, 1968), 1977.

17. Mormann, T. Topology as an Issue for History of Philosophy of Science, In New Challenges to Philosophy of Science Volume 4 of the series The Philosophy of Science in a European Perspective, pp. 423-434, 2013.

18. Porphyry. Introduction (or Isagoge) to the logical Categories of Aristotle, vol. 2, pp. 609-633, (this text was transcribed by Roger Pearse, Ipswich, UK, 2007), see:

http://www.tertullian.org/fathers/porphyry isagogue 02 translation.htm\#c, 1853.

19. Schulte, O., and J. Cory J. Topology as Epistemology, In B. Smith and W. Żełaniec, Topology for Philosophers, The Monist 79 (1), 1996, pp. 141-147.

20. Skowron, B. The Forms of Extension, In M. Szatkowski M. and M. Rosiak (eds), Substantiality and Causality, Philosophische Analyse/Philosophical Analysis, Berlin/Boston: De Gruyter, 2014, pp. 175-187.

21. Skowron, B. Using Mathematical Modeling as an Example of Qualitative Reasoning in Metaphysics. A Note on a Defense of the Theory of Ideas, Annals of Computer Science and Information Systems 7, pp. 65-68, 2015.

22. Skowron, B. Mereotopology, In J. Seibt, S. Gerogiorgakis, G. Imaguire, and H. Burkhardt (eds.), Handbook of Mereology, Philosophia, München: De Gruyter, pp. 354-361, 2017.

23. Strange, S. K. 'Introduction' to Porphyry: On Aristotle's Categories, London: Bristol Classical Press, 1992

24. Wittgenstein, L. Tractatus logico - philosophicus, (first ed. [1921], Logisch - philosophische Abhandlung, In Annalen der Naturphilosophie, Warszawa: BKF, PWN, 1997.

25. Woleński, J. Kierunki i metody filozofii analitycznej [Directions and Methods of Analytical Philosophy], In J. Perzanowski (ed.), Jak filozofować? [How to Philosophise?],

Warszawa: PWN, pp. 30-77, 1989

26. Woleński, J. W stronę logiki [Towards Logic], Kraków: Wyd. AUREUS, 1996.

27. Woleński, J. Epistemologia [Epistemology], Warszawa: Wyd. Naukowe PWN, 2005.

28. Wolff, Ch. Philosophia prima sive Ontologia metodo scientifica pertractata qua omnis cognitionis humanae principia continentur, Veronae (comp. Pars I, Caput III: De notione entis), 1789.

29. Wolniewicz, B. Hermeneutyka logiczna [Logical Hermeneutics], Studia Filozoficzne 7, pp. 2740, 1983.

30. Wolniewicz, B. Ontologia sytuacji [Situation Ontology], Warszawa: PWN, 1985.

31. Wolniewicz, B. Logic and Metaphysics. Studies in Wittgenstein's Ontology of Facts, Warszawa: Polskie Towarzystwo Semiotyczne (Ed. by Polish Semiotic Association), 1999.

\section{Notes}

1. The Reader can find Ingarden's investigations on ideas in Ingarden [9], Chapter II, $\S 9$ and also in other chapters. 
2. This is the case, for example, according to Hartmann and - probably - is confirmed by the science of facts (to follow Husserl's terminology). However, as philosophers, we cannot insist on such a position. Personally, I think that when, for example, angels are said to be immaterial and rational, the term "rational" means something different from the human being defined as animal rationale.

3. Comp. [29]. Wolniewicz writes in the abstract of his paper: "Rules and evaluation criteria for the interpretation of philosophical systems are called hermeneutics. The logical interpretation of a system is aimed at revealing its logical structure. Its hermeneutical value depends on several parameters: range, coherence, naturalness, additional assumptions, and concordance with other systems. For illustration purposes, significant fragments of two known metaphysical systems were interpreted in this way: Hume and Wittgenstein."

4. Formal details and a discussion of these issues can be found in [14, pp. 412-414], while the definition of a lattice composed of topological spaces can be found on p. 405. 